Proc. Indian Acad. Sci. (Earth Planet. Sci.), Vol. 90, No. 3, November 1981, pp. 291-304. (C) Printed in India.

\title{
Horizontal moisture distribution from TIROS-N high resolution infrared sounder (HIRS)
}

\author{
VIJAY K AGARWAL and ASHAJAYANTHI LOGANATHAN \\ Meteorology Division, Space Applications Centre (ISRO), Ahmedabad 380 053, India \\ MS received 5 September 1980 ; revised 17 J une 1981

\begin{abstract}
A direct linear relationship between water vapour content of lower, middle and upper-middle troposphere respectively with the radiances for $8.3,7.3$ and $6.7 \mu \mathrm{m}$ spectral observations has been attempted. From the atmospheric simulations such a relationship is found to exist with a good degree of correlation and is seen to be quite insensitive to temperature changes. Such an approach is used to interpret the water vapour imageries obtained from TIROS-N sounder through construction of detailed water vapour distribution maps.
\end{abstract}

Keywords. Water vapour ; infrared rudiation; IR radiance; TIROS-N HIRS; water vapour distribution.

\section{Introduction}

The TIROS-N/NOAA-6 series of polar orbiting weather satellite have an operational vertical sounding system (TOVS) which performs spectral measurements in various bands (IR and Microwave) for sensing vertical temperature and moisture profiles. In this paper, we are concerned with the infrared (IR) measurements specially connected with water vapour absorption. TIROS-N vertical sounder has $8.3,7.3$ and $6.7, \mathrm{~m}$ spectral bands besides the thermal window at $11.11 \mu \mathrm{m}$ which are relevent to water vapour observations. These constitute part of the 20 channel IR measurements performed by high resolution infrared radioneter (HIRS).

Since the density dependence of the transmittance function of the atmosphere for IR radiation to reach satellite height, is highly nonlinear, the problem of extracting mixing ratio for non-uniformly mixed gases (e.g. water vapour) becomes quite involved. The standard techniques employing 'inversion algorithm' (Smith and Woolf 1976) which are essentially iterative in nature and require a lot of efforts do not present a simplistic approach for a quick interpretation of an imagery made from these radiances. Moreover, for several applications like estimation of vertical transport of moisture in the studies for cloud convection 
and severe weather phenomenon, we require only horizontal gradients which are ensier to obtain if a water vapour map could be constructed from these measurements. Our aim therefore, is to get a simple, relationship between these radiances and the associated water vapour distribution.

Though il qualitative interpretation of WV imagery has been attempted as early al 1972 (Allison et al 1972) using data available from $6.7 \mu \mathrm{m}$ spectral channel onboard NIMBUS-5 the quintitative calculations have been attempted only in 1978 (Poc ef al 1978). The results have been quite encouraging and indicate a linear relationship between $6.7 \mu \mathrm{m}$ radiances and water vapour in $600-350 \mathrm{mb}$ layer of the troposphere.

We continue an extension of this work to TIROS-N HIRS data and try to identify the appropriate contributory layer for each of the channel under discussion. Morcover, we make an attempt to get lower level water vapour from a combination of $11.11 \mu \mathrm{m}$ measurement along with other measurement in the same window.

We proceed by looking at the problem from the atmospheric simulations and then check the actual HIRS data against a few available radiosonde observations. A typical water vapour imagery and a resultant water vapour distribution map are also presented as examples.

The ditit has been received by ISTRAC terminal at SHAR and the datapreprocessing to get the WV imagery were also tried as part of the programme. Our approach to this attempt is also discussed in this note.

\section{Water vapour IR radiances}

The spectral radiances for $11.11,8.3,7.3$ and $6.7 \mu \mathrm{m}$ spectral channels are dependent upon vertical temparature and humidity profile of the atmosphere. Using radiative transfer theory, the radiance received at satellite height from the intermediate atmosphere which is conveniently assumed $n$-layered, can be written as : (for spectral frequency $v$ )

$$
I(\nu)=B\left(p, T_{\mathrm{s}}\right) \tau_{\mathrm{s}}(\nu, 0)+\int_{\tau_{\mathrm{s}}(\nu, 0)}^{1} B\left(\nu, T_{\mathrm{h}}\right) d \tau_{\mathrm{h}}(\nu, z)
$$

where $T_{\mathrm{s}}=$ surface temparature, $\quad T_{\mathrm{t}}=$ temperature at height $Z$,

$\tau_{B}=$ total transmittance at surface, $\tau_{h}=$ total transmittance at height $Z$ to top of atmosphere

$B(v, T)=$ Plank's radiance function for a particular layex at height $Z$ is

$$
B(\nu, T)=\frac{c \nu^{3}}{\left[e^{\mathrm{ln} /} / \mathrm{k}^{\mathrm{t}}-1\right]}
$$

Where $c$ is constant.

The transmittance function $\tau$ depends upon the absorption coefficient (for spectral frequency $\nu$ ) which in turn depends upon the concentration of absorbing 
material. The dependence is nonlinear because the whole profile comes into consideration i.e. the radiance is a functional of temperature and humidity.

Since larger concentration of water vaopur will lead to a higher absorption, the effective radiation reaching satellite radiometer will be less. Therefore, a radiance map from 8.3, 7.3 and $6.7 \mu \mathrm{m}$ spectral channels can give an overall qualitative ideas about the areas rich in moisture. Such qualitative observations have been quite useful in getting some insight into the tropospheric dynamics (Smith and Woolf 1979)

Attempts to find quantitative relationship between radiances in $6.7 \mu_{\mathrm{m}}$ spectral observation from NIMBUS-5 and the water vapour content have been quite successful (Poc et al 1978). Both simulated as well as observed radiances exhibit a high degree of correlation with the total water vapour content in $600-350 \mathrm{mb}$ layer. It is also reported that this relationship does not exhibit any appreciable temperature dependence.

\subsection{Contributory layers}

The integral term in equation (1) despite its complicated structure has some conforting features. The spectral transmittance function $\tau(v)$, has a structure such that the contributions only from a part of the troposphere are important especially for the frequencies of our interest. In other words, the derivative function, $\partial \tau / \partial \ln p$, determining the variation of transmittances with height, has peak in some layer of the troposphere for these spectral frequencies. The typical behaviour of this function, called the weighting function, is shown in figure 1.

From the structure of these weighting functions, it can be seen that

$11.11 \mu \mathrm{m}$ channel is mostly affected by water vapour (WV) and temperatures in lowest layer, with a peak at $1000 \mathrm{mb}$,

$8.3 \mu \mathrm{m}$ has significant contributions from surface to $700 \mathrm{mb}$ with peak at $900 \mathrm{mb}$,

$7.3 \mu \mathrm{m}$ has significant contributions from 850 to $550 \mathrm{mb}$ with peak at $700 \mathrm{mb}$.

$6.7 \mu \mathrm{m}$ channel gets most of its contribution from 600 to $350 \mathrm{mb}$ layer with peak at $500 \mathrm{mb}$.

\subsection{Transmittance simulation}

The atmospheric transmittances for a tropical standard atmosphere (table 1) with varying humidity content have been calculated using LOWTRAN-3B (Mc Clatchy et al 1976) in band approximation (Mc Clatchy et al 1976). The atmspoheric transmittance incorporates effects of water vapour absorption, absorption due to water vapour continuum, and absorption due to uniformly mixed gases. 


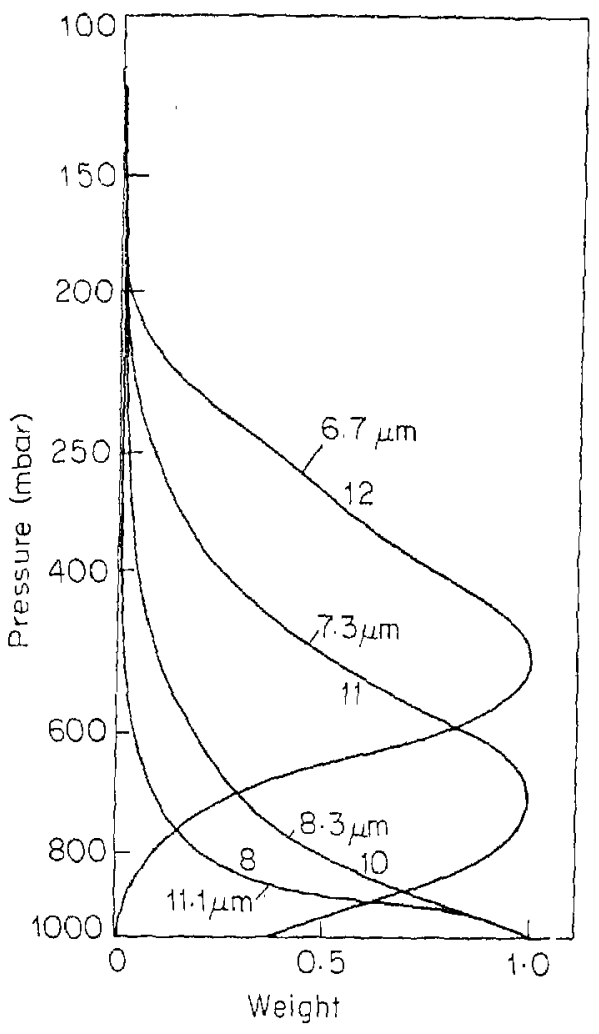

Figure 1 . Weighting functions, $\partial \tau / m p$, for $11 \cdot 11,8 \cdot 3,7 \cdot 3$ and $6 \cdot 7 \mu \mathrm{m}$ spectral channels (Smi th and Woolf 1979).

Table 1, Standard tropical atmosphere

\begin{tabular}{ccccccccc}
\hline $\begin{array}{c}h \\
(\mathrm{Km})\end{array}$ & $\begin{array}{c}P \\
(\mathrm{mb})\end{array}$ & $\begin{array}{c}T \\
\left({ }^{\circ} \mathrm{K}\right)\end{array}$ & $\begin{array}{c}h \\
(\mathrm{Km})\end{array}$ & $\begin{array}{c}P \\
(\mathrm{mb})\end{array}$ & $\begin{array}{c}T \\
\left({ }^{\circ} \mathrm{K}\right)\end{array}$ & $\begin{array}{c}h \\
(\mathrm{Km})\end{array}$ & $\begin{array}{c}P \\
(\mathrm{mb})\end{array}$ & $\begin{array}{c}T \\
\left({ }^{\circ} \mathrm{K}\right)\end{array}$ \\
\hline 0 & 1013 & 300 & 4 & 633 & 277 & 8 & 378 & 250 \\
1 & 904 & 294 & 5 & 559 & 270 & 9 & 329 & 244 \\
2 & 805 & 288 & 6 & 492 & 264 & 10 & 286 & 237 \\
3 & 715 & 284 & 7 & 432 & 257 & 11 & 247 & 230 \\
\hline
\end{tabular}

The assumed moisture profiles in $\mathrm{mm}$ of precipitable water for a $1 \mathrm{Km}$ thick layer are shown in figure 2 . In all eight profiles have been used and radiance calculated using equation (1) where the integral is replaced by a sum over layers, each $1 \mathrm{~km}$ thick. These radiances are tabulated below (table 2). In calculating these radiances we have assumed a nominal hand width of $20 \mathrm{~cm}^{-1}$. It is found that the results from the explicit transmittance functions of Moskalenko (1969) and the Lowtran calculations agree remarkably well. 


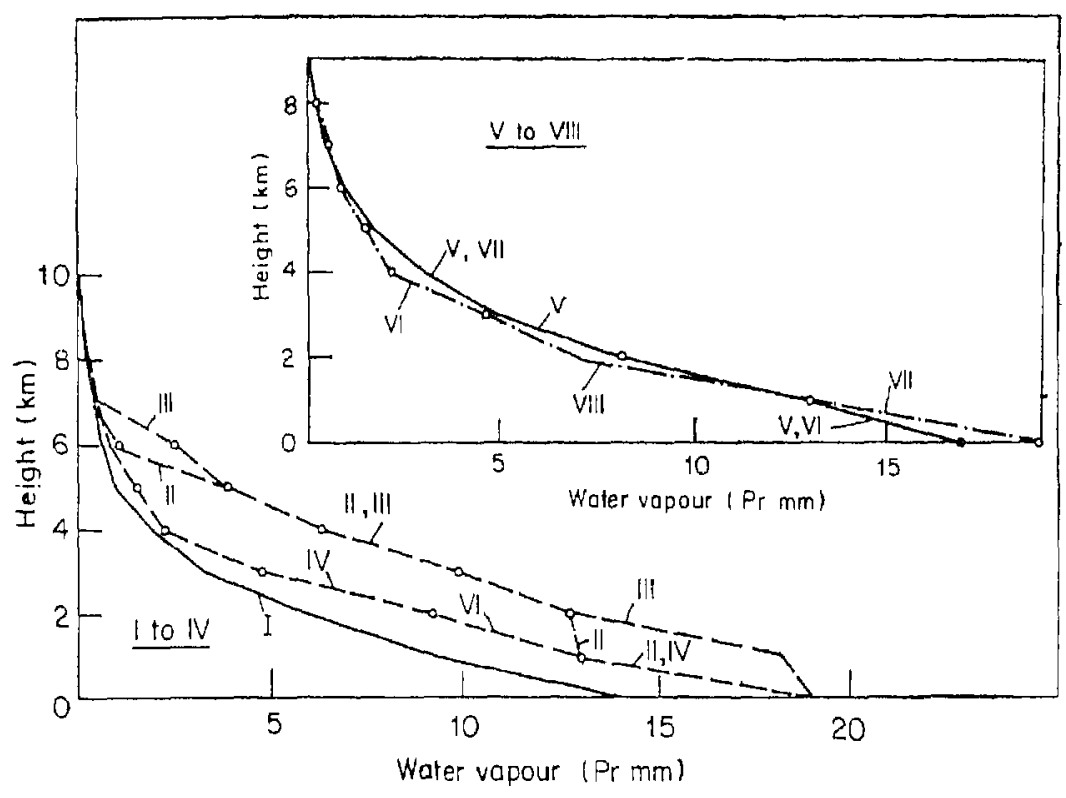

Figure 2. Moisture Profiles (in $\mathrm{mm}$ of precipitable water for $1 \mathrm{Km}$ thick layer).

Table 2. Radiance (in $\mathrm{mW} / \mathrm{m}^{1} / \mathrm{St} / \mathrm{Cm}^{-2}$ ) for eight moisture profiles

\begin{tabular}{lrrrrrrrrr}
\hline $\begin{array}{l}\text { Central } \\
\text { wave } \\
\text { length }\left(\mu_{\mathrm{m}}\right)\end{array}$ & I & II & III & IV & V & VI & VII & VIII \\
\hline 11.11 & 114.21 & 110.35 & 110.15 & 112.31 & 112.46 & 112.65 & 112.48 & 112.73 \\
8.3 & 56.49 & 53.14 & 52.46 & 54.95 & 54.80 & 55.15 & 54.90 & 55.29 \\
7.3 & 20.68 & 17.55 & 16.85 & 19.21 & 18.64 & 19.27 & 18.51 & 19.74 \\
6.7 & 7.43 & 6.68 & 6.56 & 6.85 & 6.62 & 6.84 & 6.84 & 6.99 \\
\hline
\end{tabular}

$2.2 a$ Relationship with water vapour. Based on the structure of weighting functions (figure 1) (Smith and Woolf 1979) and the earlier expectation that the various spectral observations will have a preferable tropospheric layer, we tried a linear relationship of the radiances in the four bands with water vapour content (in cms of precipitable water) of appropriate tropospheric layers. The results are summarised in table 3. Negative correlation coefficient $(x)$ means a decreasing $R$ for increasing WV. A value of $\mathrm{I}$ (magnitude) greater than 0.7 exhibits a good correlation.

In table 3, we have listed the correlation coefficient $r$ and $\chi^{2}$ of the best linear fit. It is immediately seen that $11.11 \mu \mathrm{m}, 8.3,7.3$, and $6.7 \mu \mathrm{m}$ spectral radiances are directly related respectively to $1000-950,1000-700,900-450$ and $700-300 \mathrm{mb}$ pressure layers of troposphere. The poorer correlation for $6.7 \mu \mathrm{m}$ is due to inaccurate 
Table 3. Relationship of WV content (in cms. of precipitable water) with observed radiances $(R=a+b W)$

\begin{tabular}{|c|c|c|c|c|c|c|c|}
\hline \multicolumn{2}{|c|}{$1000.950 \mathrm{mb}$} & \multicolumn{2}{|c|}{$1000-700 \mathrm{mb}$} & \multicolumn{2}{|c|}{$900-450 \mathrm{mb}$} & \multicolumn{2}{|c|}{$700-300 \mathrm{mb}$} \\
\hline$r$ & $x^{2}$ & $r$ & $x^{2}$ & $r$ & $x^{2}$ & $r$ & $x^{2}$ \\
\hline-0.87 & 0.02 & -0.85 & 0.10 & -0.86 & 0.40 & -0.84 & 0.60 \\
\hline-0.83 & 0.20 & -0.98 & 0.3 & -0.97 & 0.20 & -0.93 & 0.50 \\
\hline-0.82 & 0.50 & -0.96 & 0.20 & -0.98 & 0.08 & -0.89 & 0.60 \\
\hline-0.70 & 0.70 & $-0.80^{*}$ & 0.60 & -0.85 & 0.60 & $-0.86^{*}$ & 0.20 \\
\hline
\end{tabular}

*Discrepancies arise because of high margin of errors involved $6.7 \mu \mathrm{m}$ transmittances.

estimation of transmittances from the band formula which arises from the very high absorption cross-section for this band. A more precise simulation utilising actual LOWTRAN algorithm is being performed and the results will be published separately.

$2.2 b$ Temperature sensitivity. Let us now briefly examine the changes in temperature profile. We will treat any physical temperature profile, $T(Z)$, for our region as a perturbed standard tropical profile, $T_{0}(Z)$.

$$
\text { i.e. } T(Z)=T_{0}(Z)+\triangle T(Z)
$$

Moreover, the temperature influences the water vapour line absorption only indirectly i.e. through pressure perturbations which change the effective equivalent sea surface absorber amount length $\Delta L$ written as (Mc Clatchy et al 1972).

$$
\Delta L=W(Z)\left[\frac{P}{P_{0}}\right]^{0.9}
$$

Where $P$ is pressure of the layer at height $Z, p_{0}$ pressure at surface and $W(Z)$ is water vapour content for the layer of thickness $1 \mathrm{~km}$.

However, since the pressure perturbations are ordinarily very mild (except for the severe weather systems where the cloud cover anyway curtails the usefulness of IR observations), $\triangle L$, will not change by 'more than $0.5 \%$ even for moderate to high moisture content. Therefore, this will effectively change the corresponding transmittance by less than $1 \%$. Therefore the total transmittance function gets its temperature variability from the WV continuum absorption with a temperature dependent band-brdadening coefficient (Mc Clatchy et al 1972),

$$
b_{\mathrm{h}}=\frac{(P)}{P_{0}}\left(0.0454 W^{2}(Z) \frac{T(Z)}{P(Z)}+0.005\right) W(Z),
$$

The temperature dependence

$$
\begin{aligned}
\frac{\partial b_{\mathrm{h}}}{\partial T} & =0.0454 W^{2}(Z) / P_{0}(Z) \\
& \lesssim 5 \times 10^{-5} \text { for } W(Z)<1
\end{aligned}
$$

also constitutes a very mild change in transmittance function for the wavelengths under consideration. Thus, the total transmittances remain largely unaffected by mild ( $\$ 10$ degrees) temperature changes. A conclusion supported by earlier study for $6.7 \mu \mathrm{m}$ (Poc et al 1978). 
Any temperature sensitivity occurring in radiance value will, therefore, largely contributed by the Plank's radiance function, $B(\nu, T)$, of (1). Considering the spectral radiance, $I$, as a function of the profile, $T(Z)$, the small perturbation over $T_{0}(Z)$ can be estimated as $\triangle I$ such that

$$
I[\nu, T]=I\left[\nu, T_{0}\right]+\triangle I\left[\nu, T_{0}, \Delta T\right],
$$

Where $I\left(\nu, T_{0}\right)=$ Radiance corresponding to the temperature profile, $T_{0}(Z)$ and $\Delta I\left[\nu, T_{0}, \triangle T\right]=$ perturbation effect on the radiance. Explicitly, using the form of the temperature weighting function, $\partial \tau / \partial \ln p$ we can approximate,

$$
\triangle I \approx \frac{h v}{k \bar{T}_{0}^{2}} \overrightarrow{\Delta T} \cdot I\left[v, T_{0}\right]
$$

where $\overline{\Delta T}$ is mean temperature perturbation over the mean layer temperature, $\overline{T_{0}}$ for standard tropical profile, pertaining to the spectral observation in frequency. The $11.11 / \mu \mathrm{m}$ channel being more sensitive to the meteorological conditions below the boundary layer $(950 \mathrm{mb})$ where the temperature deviations are most pronounced, the WV and temperature variation cannot be easily separated. From (6), we see that a change of $\overline{\Delta T} \sim 1^{\circ}$ will correspond to a change in radiance of about $1.6 \mathrm{~mW} / \mathrm{St} / \mathrm{m}^{2} / \mathrm{cm}^{-1}$ for an $I\left(\mu, T_{0}\right)=110 \mathrm{~mW} / \mathrm{St} / \mathrm{m}^{2} / \mathrm{cm}^{-1}$. On the other hand, the $W . V$ content in the lowest layer varies from 1.8 to $4.0 \mathrm{~cm}$ in most of the oceanic area in the tropical belt.

Over oceanic regions where sea surface temperature varies $\pm 3^{\circ}$ over an average of $300^{\circ} \mathrm{K}$, the two effects are hardly separable as they are. However, the land-sea contrast is easily visible because of high temperature difference. The $8 \cdot 3 \mu \mathrm{m}$ spectral radiances over oceanic area will exhibit a meager variance except that the general climatological perturbation of $\overline{\Delta T} \sim 1-2^{\circ}$ over $T_{0}$ will modify the constant $a_{0}$ for our region (India). Barring the cloud formation where the IR observations anyway are not of much use, the 6.7 and $7.3 \mu_{\mathrm{m}}$ channels get least affected by surface temperature variations, though the land and sea area can still be distinguished (for example see the series of imagery in figure 4). Therefore, over one type of surface (i.e. either land, sea or snow), the lacal (in horizontal area) variation in radiances will reflect a variation of water vapour only. Details of the temperature sensitivity of the water vapour measurements from these spectral observations will be dealt with separately and presented elsewhere.

\section{TIROS-N-HIRS data processing and calibration}

In this section, we briefly summarise the data processing and calibration efforts made to get a WV imagery from HIRS data

TIROS-N-HIRS has a cross-track scan coverage of $\pm 1100 \mathrm{~km}$ about the nadir with a scan time of 6.4 seconds for each scan line. This slow scan causes a shift of about $0.4^{\circ}$ in latitude from scan line to scan line (in $5^{\circ} \mathrm{S}$ to $30^{\circ} \mathrm{N}$ latitude belt). Since the HIRS IFOV (Instant Field of View) is about $0.2^{\circ}$ in latitude (at nadir position), the HIRS imagery will not show overlapping data coverage, though the individual lines will be exhibited side by side.

\subsection{Data type}

HIRS data for all 20 channels is available as a string of 13 bitdata stream (a total of 288 bits constructed from selected 36 words of 8 bits each from a single ToVs data minor frame). This string constitutes one scan spot and each scan line is composed of 64 such spots. Out of these 64 spots 56 have earth views and remaining calibration and other information. In every set of 40 lines, three lines are radiometric observations of the standard 
calibration targets (sky, cold body and an internal warm body). A satellite time code is made available once in a major frame which is constituted of 320 minor frames (rate 0.1 second per minor frame) (Lauritson et al 1979).

\subsection{Data preprocessing}

The raw digital data recorded at the tracking station is subjected to data preprocessing and data validation before icalibration as a first step to an imagery generation. The data preprocessing accomplishes the following tasks:

- extraction of time information,

- raw data quality checks and missing data identification,

- collation of HIRS data words from each TOVS minor frame and spectral separation of each radiometric channel,

- composition of scan lines consisting of earth scan,

- separation of calibration information,

- preliminary corrections to data sets by removing spurious data points, suitable flags are raised for future applications,

- earth location is performed using the time information and the apriorily known satellite ground trace (at present this is being done manually)

- scan line reconstruction to correct for unsensed area because of unequal instant field of view (IFOV) and the radiometric incremental step. (The 56 earth scans are replaced by 82 scan spots)

- conversion of raw digital counts to calibrated radiances.

The detailed data processing-activity is shown in figure 3.

The slow scan corrections are incorporated in the earth location part by updating the latitudes at nadir of each scan line. The geometric deformations. due to earth curvature are not being corrected at present. To avoid these problems we set two subsatellite points at $\pm 40^{\circ}$ about nadir for radiometric look angle.

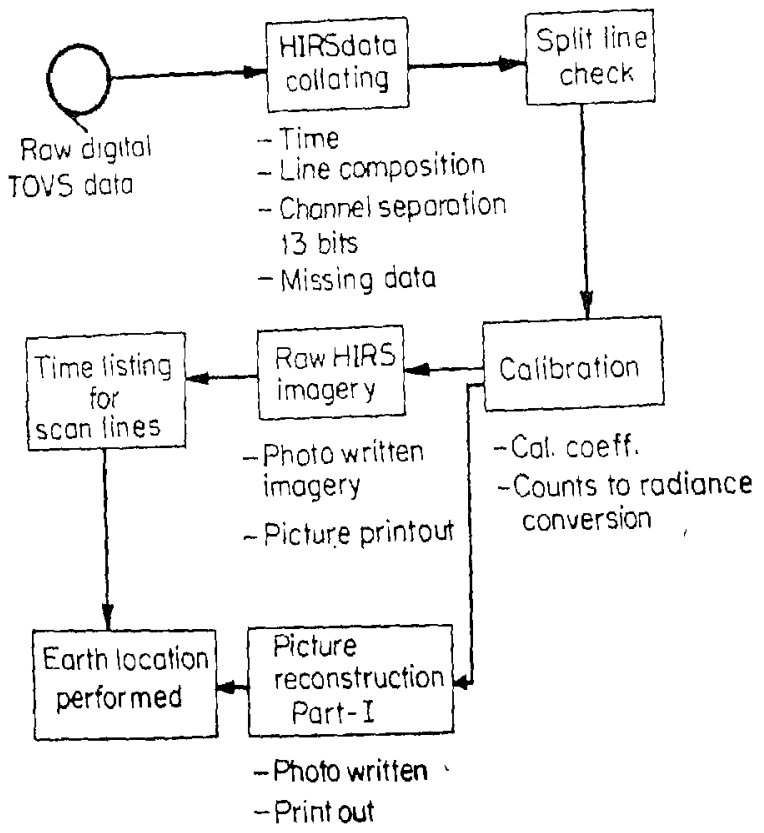

Figure 3. TIROS-N HIRS data processing flow diagram 


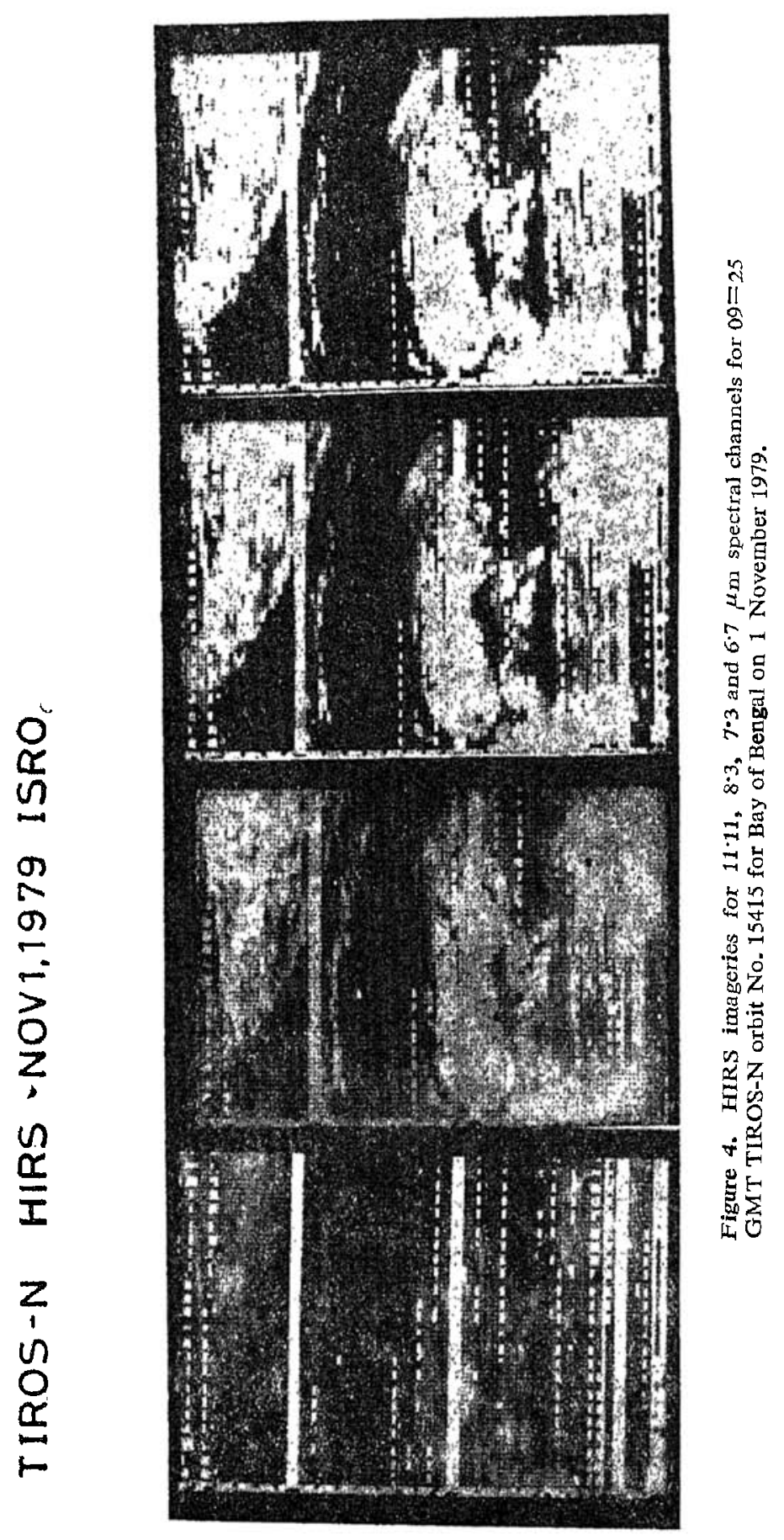




\subsection{Water vapour imagery}

The calibrated radiances for all the four channels are photowritten to construct imageries. An example is shown in the set of 4 pictures in figure 4 . The satellite pass is at $09=25$ GMT on Nov. 1st, 1979 passing over Bay of Bengal. This pass has an adequate coverage of a cyclonic storm forming off the Madras coast as can be seen from the $11.11 \mu \mathrm{m}$ imagery.

These imageries can also be printed out by a computer printer in a gross form as shown in figure 5 for $11.11 \mu \mathrm{m}$ channel. The land water boundaries are clearly demarcated save the area covered by clouds. The various symbols represent radiance value in incremental steps as indicated. The picture printout is an useful tool for water vapor map construction in view of the linear relationship established between radiance and WV content of the significant layers. The area marked by boxes correspond to the 'test-sites' where the radiosonde data is available for data validation as discussed in next section.

\section{Water vapour distribution from HIRS imagery}

The linear relationship between radiances and the water yapour content (in $\mathrm{cm}$ of precipitable water) of suitable tropospheric layer,

$$
R=a+b W \text {, }
$$

established in $\$ 2$ using simulated results and the constants derived there are used to estimate water vapour content from the HIRS imagery for a particular TIROS-N pass over Bay of Bengal (series of imageries shown in figure 4). The water vapour

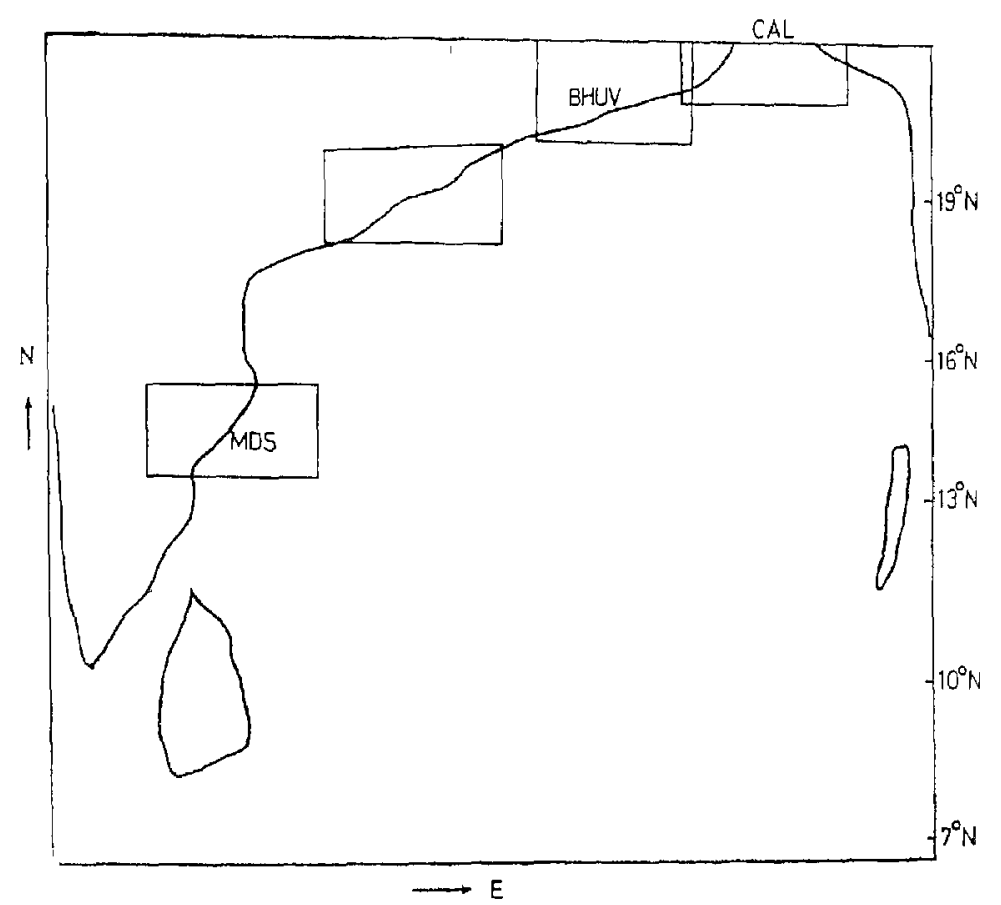

Figure 5. Sample computer picture printout for $11 \cdot 11 \mu \mathrm{m}$ spectral cbannel for 1 November 1979 Bay of Bengal data. 
estimations are compared with the radiosonde observations at a few "test sites". We have chosen the following coastal radiosonde stations-Calcutta $(22.34 \mathrm{~N}$, $88 \cdot 24 \mathrm{E})$, Bhubaneshwar $(20.15 \mathrm{~N}, 85 \cdot 52 \mathrm{E})$, Madras (13 04N, 80.17E) and Vishakhapatnam $(17.42 \mathrm{~N}, 83.20 \mathrm{E})$, and Port Blair $(11.41 \mathrm{~N}, 92.43 \mathrm{E})$. For the purpose of comparison, we have assumed that the coastal area represent the water vapour content of nearby oceanic area also at least for middle and upper troposphere and that the water vapour distribution does not show a drastic change within an area of $250 \times 250 \mathrm{~km}$. Therefore we assume that even non-concurrent observations ( $9 \mathrm{GMT}$ for satellite and $12 \mathrm{GMT}$ for radiosonde) will not give significant changes in WV distribution.

Table 4 summarises the results of these comparisons. We have attempted a rough temperature deviation correction (with respect to temperature profile of table 2 and local climatological averages) also. The observed mean radiosonde temperature deviation is also listed.

The comparative study presented above, stresses the usefulness and strength of the direct correlation of water vapour and satellite radiometric radiances. The temperature corrections to the radiances for $8.3,7.3$ and 6.7 are seen to be as expected, except near Madras where the temperatures are relatively more than the standard values. Based on this analysis, a water vapour map for Bay of Bengal using figure 4 is presented in figures $5,6,7,8$.

\section{Conclusions}

We have presented an attempt for quantitative interpretation of water vapour imagery in $8.3,7.3$ and $6.7 \mu \mathrm{m}$. spectral bands of TIROS-N HIRS. The water

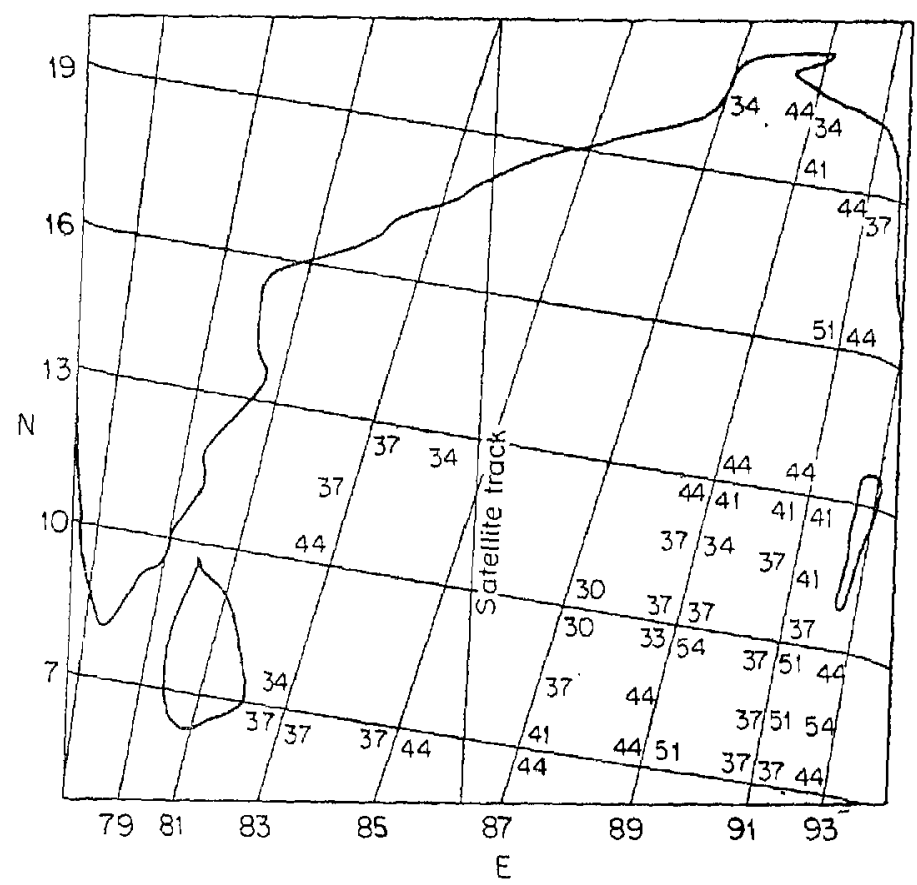

Figure 6. Water vapour map for $1000-700 \mathrm{mb}$, Bay of Bengal 1 November 1979. 
Table 4. Comparison of satillite estimates of WV contents and radiosonde observations

\begin{tabular}{|c|c|c|c|c|c|c|}
\hline N. Station & $\begin{array}{l}\text { Wave length } \\
(/ / \mathrm{m})\end{array}$ & $\begin{array}{c}\text { Radiance } \\
\text { observed } \\
\left(\mathrm{mW} / \mathrm{m}^{2} / \mathrm{st} / \mathrm{cm}^{-1}\right)\end{array}$ & $\begin{array}{l}\text { Radiosonde } \\
\text { (WV Cms) }\end{array}$ & $\begin{array}{l}\text { Estımated } \\
\text { (WV cns) }\end{array}$ & $\begin{array}{l}\text { Corrected } \\
\text { for } T_{0} \\
\text { (cms.) }\end{array}$ & $T_{0}$ \\
\hline \multirow[t]{3}{*}{ Calcutta } & 8.3 & 51.6 & 4.0 & 4.95 & 4.6 & -1.5 \\
\hline & 7.3 & 18.6 & $>3.1$ & 4.54 & 4.24 & -2.5 \\
\hline & 6.7 & 7.25 & - & 0.6 & - & - \\
\hline \multirow[t]{3}{*}{ Bhubaneshwar } & 8.3 & $43.6 \mathrm{c}$ & 3.53 & - & - & -2.5 \\
\hline & 7.3 & $16.7 \mathrm{c}$ & 4.43 & 6.3 & 5.8 & -3.0 \\
\hline & 6.7 & 7.1 & $>0.8$ & 1.07 & - & - \\
\hline \multirow[t]{3}{*}{ Madras } & 8.3 & - & 4.34 & - & - & - \\
\hline & 7.3 & - & 5.1 & - & - & - \\
\hline & 6,7 & $5.3 \mathrm{c}$ & $>1.53$ & - & - & - \\
\hline \multirow[t]{3}{*}{ Port-Blair } & 8.3 & $48.0 \mathrm{~d}$ & 4.02 & 4.78 & 4.1 & -3.0 \\
\hline & 7.3 & $15.6 \mathrm{~d}$ & 4.32 & 3.9 & 3.4 & -4.0 \\
\hline & 6.7 & 7.3 & $>0.36$ & 0.44 & - & - \\
\hline \multirow[t]{3}{*}{ Yishakapatnam } & 8.3 & - & 4,46 & - & - & - \\
\hline & 7.3 & - & 5.70 & - & - & - \\
\hline & 6.7 & $5,3 c$ & $>1.2$ & - & - & 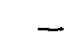 \\
\hline
\end{tabular}

$c=$ cloud contamination and absence of data

$\mathrm{d}=$ geometric deformation and limb corrections not included

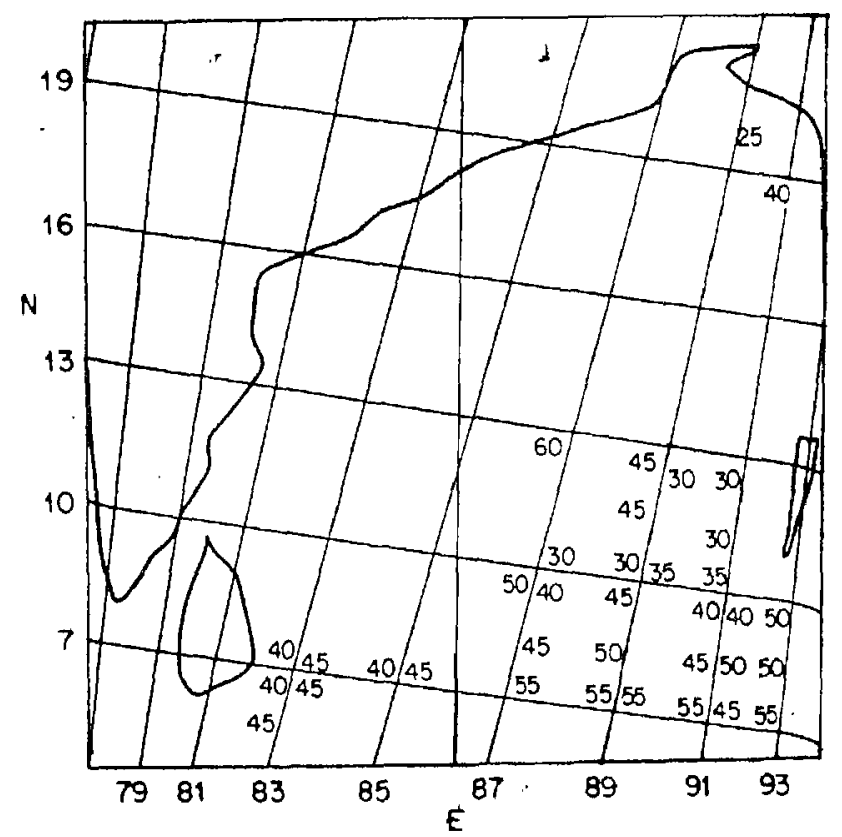

Figure 7. WV map for $900-450 \mathrm{mb}$, Bay of Bengal 1 November 1979. 


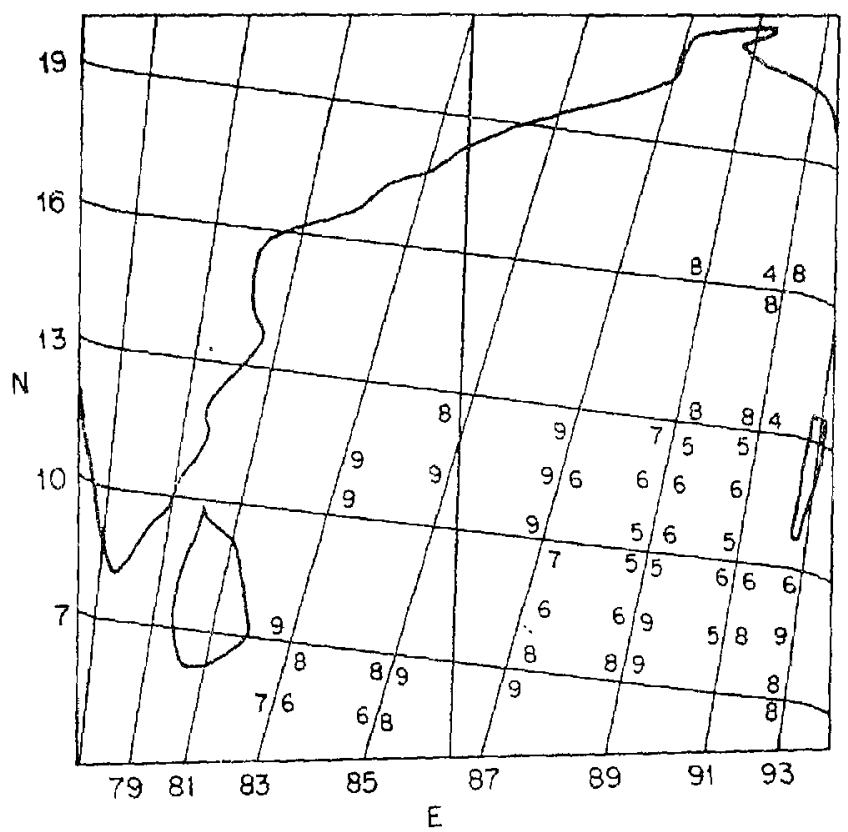

Figure 8. WV map for $700-300 \mathrm{mb}$, Bay of Bengal 1 Noyember 1979.

vapour distribution. for $1000-700 \mathrm{mb}, 900-450 \mathrm{mb}$ and $700-300 \mathrm{mb}$ regions of troposphere are readily available from these imageries. The cloud boundaries are delineated by $11 \cdot 11 \mu \mathrm{m}$. thermal IR channel.

The variation in water vapour distribution can lead to an idea about the extent of divergence (in upper levels) and convergence (in lower levels) taking place for a cloud system.

\section{Acknowledgement}

The authors are greatly indebted to Dr T A Hariharan, Meteorology Division, Space Applications Centre for continued encouragement and critical analysis during the course of this work. The data was received from the SHAR Centre of ISRO and we acknowledge all the staff of the Ground station without whose help this work would not have been possible. The calibration work in its initial stages was taken up by late Dr VK Garde, Meteorology Division, Space Applications Centre. Useful suggestions and comments of other colleagues of Meteorology Division are gratefully acknowledged. The cloud imagery were prepared by photographic facility of IPAD, SAC.

\section{References}

Allison J Lewis, Joseph Steranka, Thomas Cherrix G and Ernest Hilsenrath 1972 Bull. Am. Met. Soc. 53526

Lauritson L, Gary J Nelson and Frank W Porto 1979 Report No. NESS-107, NOAA (USA)

McClatchy R S R W Fenn, Selby J E A, Garing J S and F E 1972 Report No. AFGL-IR-72-049 Environment Research Paper No. 411, Air Free Geophysics Lab. USAF, Vol. 3

MeClatchy R S R W Fenn, Sejby J E A, Garing I S and F E 1976 Report No. AFGL-IR-76-025 Air Force Geophysics Lab. USAF

Moskolenko N I 1969 Translated from Atmospheric and Oceanic Physics (USSR) 51179

Smit W L and Woolf H M 1976 J. Atmos. Sci. 331137

Smith W L and Woolf H M 1979 Bull Am. Met. Soc. 601177

Poc M M, Roullean M, Scott N and Chedin A 1978 Paper No. C. 3.5 in COSPAR, at Injbruck, Austria 